\title{
骨架环肽的化学合成研究进展
}

\author{
司岩岩 $a, b$ 郭 叶 $b$ 李海燕 $b$ 孙浩源 $a, c$ 方葛敏 ${ }^{*, a, b}$ \\ $\left({ }^{a}\right.$ 中国科学院合肥物质研究院强磁场科学中心 合肥 230031) \\ ( ${ }^{b}$ 清华大学化学系 北京 100084) \\ $\left({ }^{c}\right.$ 辽宁大学生命科学院 沈阳 110036)
}

\begin{abstract}
摘要 骨架环肽是线性肽的 $\mathrm{C}$ 端和 $\mathrm{N}$ 端通过酰胺键进行首尾环合而形成的环状分子. 研究者从细菌、真菌、植物和动 物中发现了大量的骨架环肽. 这种首尾环合的结构, 使得骨架环肽具有很好的酶稳定性、热稳定性和化学稳定性, 部分 骨架环肽具有细胞膜通透性. 骨架环肽分子异常的稳定性和高效的生物活性，使得其成为目前药物领域的研究热点. 为了更深入地研究它们的结构和功能, 骨架环肽的制备成为一个重要问题. 概述了化学合成骨架环肽的一些方法, 包 括: (1)固相环合策略; (2)液相环合策略; (3)分子内自然化学连接策略, 并对这些方法的特点和效率进行了讨论比较.

关键词 骨架环肽; 环化; 自然化学连接
\end{abstract}

\section{Recent Advances in Chemical Synthesis of Backbone Cyclized Peptides}

\author{
Si, Yanyan ${ }^{a, b}$ Guo, Ye Li, Haiyan $^{a} \quad$ Sun, Haoyuan $^{a, c} \quad$ Fang, Gemin ${ }^{*, a, b}$ \\ ( ${ }^{a}$ High Magnetic Field Laboratory, Chinese Academy of Sciences, Hefei 230031) \\ ( ${ }^{b}$ Department of Chemistry, Tsinghua University, Beijing 100084) \\ ( ${ }^{c}$ College of Life Science, Liaoning University, Shenyang 110036)
}

\begin{abstract}
Backbone cyclized peptides belong to a family of circular polypeptide molecules in which the carboxyl and amino termini are covalently linked by an amide bond. Over the last almost 20 years, the backbone cyclized peptides have been discovered in bacteria, fungi, plants and animals. Compared with their linear precursors, the backbone cyclized peptides have a head-to-tail cyclic backbone enabling them to resist enzymatic degradation and to improve their thermal and chemical stability. Remarkably, some of them even have cell membrane permeability. Due to their exceptionally intracellular stability and potent bioactivities, backbone cyclized peptide is emerging as one of the most interesting molecules in the area of drug discovery. To study the structure and function of backbone cyclized peptides in detail, it is necessary to develop efficient approaches for the synthesis of these molecules. Herein, the recent advances in chemical synthesis of backbone cyclized peptides with respect to cyclization strategies are reviewed, including solid phase-based cyclization, liquid-phase cyclization, and intramolecular native chemical ligation.
\end{abstract}

Keywords backbone cyclized peptides; chemical synthesis; native chemical ligation

骨架环肽(Backbone cyclized peptides)是线性多肽 的头尾通过酰胺键相连而形成的环状分子. 与线性多肽 相比, 骨架环肽具有较为刚性的环骨架结构特征, 因而 对蛋白水解酶稳定性显著提高, 甚至部分骨架环肽具有 独特的细胞膜通透性. 正是这一原因, 骨架环肽成为当 今国际药物领域的重要研究对象 ${ }^{[1 \sim 7]}$. 早在第二次世界 大战期间, 苏联科学家高斯就发现由 10 个氨基酸组成 头尾环合而成的短杆菌肽具有抑制细菌生长的功能 ${ }^{[8]}$. 它是二战期间治疗伤病人伤口感染的主要药物, 挽救了
无数人的生命. 短杆菌肽的发现成为环肽研究的重要历 史性事件. 随后, 研究者在细菌、真菌、植物和动物中 均发现环肽, 其中许多不乏药物功能. 例如, 由 11 个氨 基酸组成的环狍素可用于器官移植中防止免疫反应; 含 有多个环状结构的乳酸链球菌肽可用于防止食品腐败; 多粘素可用于治疗肠胃疾病等 ${ }^{[9]}$.

骨架环肽的天然功能是宿主防御作用，即通过抑制 外来生物的生长来保护本物种的生存和延续. 通过活性 实验, 研究者发现骨架环肽还具有一些独特生物功能,

* E-mail: fgmsxy@gmail.com

Received November 1, 2013; revised November 19, 2013; published online December 6, 2013. 
可用于治疗人类疾病. 如存在于植物中的环多肽 (Cyclotide)具有助子宫收缩活性、抗菌性、抗 HIV 活性 以及抗肿瘤活性 ${ }^{[10]}$. 然而, 从生物中得到的骨架环肽可 能对人体产生生物毒性, 因此多数不能直接用于临床试 验, 而需要对其结构进行改造. 例如, 为了降低 Cyclotide 的生物毒性, 研究者需要对其个别位点进行突 变或者通过 “嫁接” 的方式将具有生物活性的外源功能 肽融合于 Cyclotide 中 ${ }^{[11]}$.

骨架环肽可以通过 3 种途径获得: 从生物体中分 离、基因重组技术和化学从头合成. 从生物体内纯化骨 架环肽的方法存在分离难度大、效率低和工作量大的缺 点. 由于骨架环肽存在特殊的头尾环合的酰胺键结构, 传统基因重组表达技术也不能直接用于骨架环肽的制 备, 需要对菌种进行再改造, 因而该方法技术难度相对 较高. 骨架环肽对菌种的毒性也会常常导致基因重组表 达失败. 此外, 生物表达含有非天然修饰的骨架环肽的 能力十分有限. 相比前两种方法, 化学从头合成骨架环 肽具有优势, 如可以任意改变氨基酸的序列, 可以实现 位点的任意突变, 以及可以任意非天然氨基酸的嵌入 等.

从环化反应的特点来看, 骨架环肽的化学合成经历 了二个阶段. 早期骨架环肽的合成是以侧链官能团全保 护的线性肽为底物, 头尾通过缩合试剂而环化. 该方法 存在许多缺点. 例如, 需要预制部分或全部保护的线性 多肽; 反应位点手性中心不能保持和容易发生多聚化副 反应. 上世纪末本世纪初, 研究者发展出化学选择性连 接环化反应制备骨架环肽的方法, 成功解决了传统缩合 法的缺陷. 虽然历史上有不少关于环肽方面的综 述 ${ }^{[12 \sim 17]}$, 但是多数是笼统介绍骨架环肽、侧链环肽和环 肽类似物的进展, 专门介绍骨架环肽的合成的综述文章 仍很少. 基于国际上最近涌现许多课题组利用新型的多 肽连接反应制备骨架环肽, 我们将着重从化学合成角度 综述骨架环肽的最新进展.

\section{1 固相环化策略}

固相环化指多肽头尾成酰胺键反应在树脂上完成. 该策略有两个明显的优点, 如降低分子间碰撞几率, 减 少分子间多聚化副反应; 减少合成中的分离和纯化的次 数. 一般来说, 多肽可采用两种方式固定于树脂上, 即 利用侧链官能基团针定树脂和利用 $\mathrm{C}$ 端羧基固定于树 脂. 前者在固相上完成多肽序列的拼接后, 脱去 $\mathrm{N}$ 端和 $\mathrm{C}$ 端保护基游离出自由氨基和羧基, 再在固相上完成 $\mathrm{C}$ 端羧基和 $\mathrm{N}$ 端氨基的缩合环化. 后者则利用主链 $\mathrm{C}$ 端羧 基针定树脂, 在多肽序列拼接完成后, 活化多肽的 C 端, 并随之与 $\mathrm{N}$ 端自由氨基发生分子内胺解环合反应. 第二
种方法环化和多肽的固相切割是同时进行的，且不需要 侧链固定, 因而比第一种方法更具优势. 需要指出, 固 相环化反应不能保证反应位点的构型完全保持, 对于易 消旋的氨基酸具有潜在的危险.

\section{1 侧链固定树脂}

利用氨基酸侧链官能团固定树脂, 线性多肽 $\mathrm{N}$ 端氨 基和 C 端羒基通过缩合反应生成环肽是固相合成骨架 环肽的常用方法. 该方法需要正交的保护基用于保护多 肽侧链功能团、 $\mathrm{N}$ 端氨基和 $\mathrm{C}$ 端羧基. 侧链功能团一般 采用对酸敏感的保护基; $\mathrm{N}$ 端氨基可采用 Fmoc; $\mathrm{C}$ 端羧 基常用对 Pd 敏感的烯丙酯结构. 具体的操作如图 1 所 示. 首先, 第一个氨基酸利用侧链官能团和树脂上官能 团反应固定于树脂; 该氨基酸的 $\alpha$-氨基以 Fmoc 保护, C端羒基采用烯丙酯保护. 接下来, 按照传统 Fmoc 固相 合成完成目标序列的拼接后, 分别用 $\mathrm{Pd}\left(\mathrm{PPh}_{3}\right)_{4}$ 、哌啶试 剂解除 $\mathrm{C}$ 端烯丙酯和 $\mathrm{N}$ 端 Fmoc 保护基. 最后, 线性多 肽首尾通过缩合反应实现环化, 并在 TFA 作用下与树 脂分离, 最终得到天然结构的环肽. 常用侧链固定树脂 的氨基酸为 $\mathrm{Asp}, \mathrm{Glu}^{[18]}, \mathrm{His}^{[19]}$ 或者 $\mathrm{Lys}^{[20]} .2011$ 年, Veerman 等 ${ }^{[21]}$ 利用 Glu 侧链针定树脂, 合成出环状人体 唾液中的组胺素, 并证明其活性是天然线性组胺素的 1000 倍. 需指出, 该策略在固相合成中常常会有二酮哌 嗪副反应，且环化反应不能确保反应中心的手性保持.

\subsection{C 端磺酰胺固定树脂}

在 Fmoc 法固相多肽合成中, 多肽 C 端羒基不能直 接采用活化酯或活化酰胺的形式来固定树脂. 这是因为 Fmoc 多肽固相合成操作过程需要使用强碱性亲核性试 剂——哌啶. 在采用 $\mathrm{C}$ 端固定树脂方式合成骨架环肽过 程中, 多肽 $\mathrm{C}$ 端连接臂必需对哌啶稳定, 且在线性肽固 相拼接后可被高效转化为活化氧酯或活化酰胺, 以实现 与 $\mathrm{N}$ 端自由氨基发生分子内环化反应. 磺酰胺结构满足 该要求, 可以用于 $\mathrm{C}$ 端针定树脂固相合成骨架环肽. 磺 酰胺对哌啶试剂非常稳定, 而经过烷基化后能转变为活 化酰胺, 可以与裸露自由氨基发生高效的胺解反应. 具 体操作如图 2 所示. 首先在完成多肽固相拼接后将 $\mathrm{N}$ 端 氨基保护基 Fmoc 转化为对酸敏感的 Trt 保护基, 接下来 分别用碘化乙腈处理磺酰胺树脂和弱酸解除 $\mathrm{N}$ 端 $\mathrm{Tr}$ 保 护基以及用有机碱催化首尾固相环合反应，最后利用强 酸 TFA 解除侧链保护基得到天然结构的骨架环肽. 1999 年, Morriello 等 ${ }^{[22]}$ 在 Merck 公司首次利用 Kenner's 磺酰 胺树脂成功合成了骨架环肽和环羧酚酸肽. 2005 年, Ganesan 等 ${ }^{[23]}$ 采用该法合成了海洋天然产物骨架环肽 kahalalide A 及类似物, 并系统研究了该天然产物的结 构功能关系. 此外, 磺酰胺树脂还被用于多粘菌素 ${ }^{[24]}$ 、 
<smiles>CC#COC(=O)C[C@H](NC(F)F)C(=O)OCc1ccccc1</smiles><smiles>[R]C1NC(=O)C(CC(=O)O)NC(=O)C1CC(=O)NC</smiles>

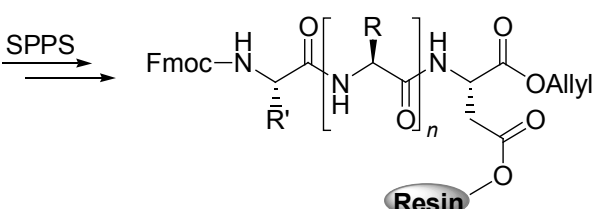

Resin

(1) $\mathrm{Pd}\left(\mathrm{PPh}_{3}\right)_{4}, \mathrm{Ph}_{3} \mathrm{SiH}$ (2) Piperidine

(1) PyBOP, DIEA (2) $\mathrm{TFA} / \mathrm{H}_{2} \mathrm{O}$

图 1 侧链固定树脂辅助多肽骨架环化

Figure 1 On-resin cyclization of peptides anchored to resin with side chains
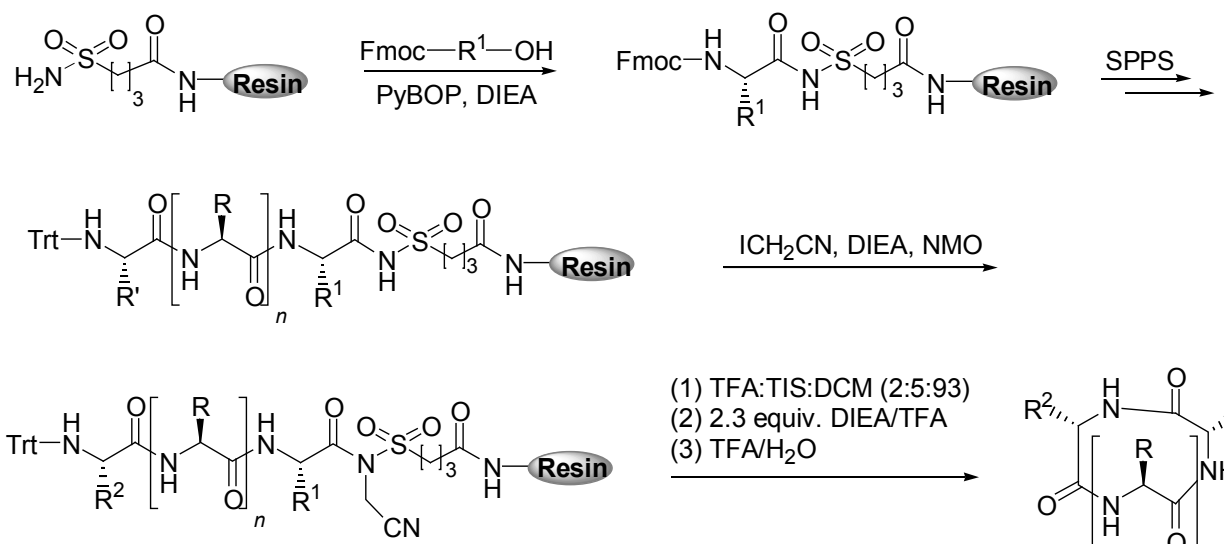

(1) TFA:TIS:DCM (2:5:93)

(2) 2.3 equiv. DIEA/TFA

(3) $\mathrm{TFA} / \mathrm{H}_{2} \mathrm{O}$

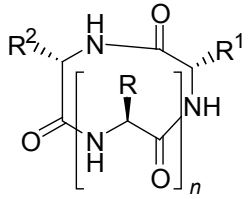

图 2 磺胺树脂用于多肽骨架环化反应

Figure 2 On-resin cyclization of peptides anchored to resin with a 'safety catch' linker at C-termini

链阳霉素等 ${ }^{[25,26]}$ 环肽的化学合成.

\subsection{C 端芳基酰基肼固定树脂}

芳基酰基肼可以通过脱氢氧化转化为活化酰胺, 氨 基可以与活化酰胺发生成酰胺键反应. 氧化过程对多数 氨基酸不造成副反应，因而原理上可用于多肽的 $\mathrm{C}$ 端固 相活化制备骨架环肽. 该反应早在 1970 年被 Birr 等 ${ }^{[27]}$ 发现, 但是长期以来并没有被多肽研究者所关注. 直到 1997 年, Langner 等 ${ }^{[28]}$ 首次利用 $\mathrm{C}$ 端芳基酰基肼合成了 骨架环七肽，并证明该方法制备骨架环肽的效率比传统 液相缩合高. 2001 年, Waldmann 等 ${ }^{[29]}$ 利用该法也成功制 备了骨架环六肽, stylostatin, 如图 3 所示. 此外, Janda 等 ${ }^{[30]}$ 并将该方法用于多种骨架环肽分子的构建. 值得 一提, 2004 年, Camareo 等 ${ }^{[31]}$ 利用芳基肼氧化活化反应 发展了 Fmoc 硫酯的合成方法. 通过结合自然化学连接 反应, Camareo 等 ${ }^{[32]}$ 最近实现了防御素的化学合成. C 端 芳基酰基肼活化环合以商业化的苯肼树脂为载体进行
固相合成，完成多肽拼接后，利用 NBS 获铜试剂氧化芳 基酰基肼实现 $\mathrm{N}$ 端氨基与 $\mathrm{C}$ 端的固相环化反应. 需注 意，该方法对位阻比较敏感，适合于反应位点位阻比较 低的氨基酸的环化，且氧化条件可能造成 Met 和 Trp 侧 链的氧化副反应发生.

\section{2 液相环化策略}

固相环化策略不适合链比较长的骨架环肽合成. 这 是由于随着肽链的增长, 固相反应的效率会显著降低. 因此，对于长链的骨架环肽高效的合成方法仍为液相缩 合. 传统的液相缩合是以侧链全保护的线性肽为原料, 通过缩合反应而完成多肽的头尾环合. 侧链全保护肽的 溶解性受序列和链长度影响大，因此缩合前需对有机溶 剂进行优化 ${ }^{[16,17]}$. 为降低分子间缩合副反应，液相缩合 的浓度一般要求严格控制. 而且，传统缩合反应位点立 体保持性差，一般适用于 C 端为 Gly 和 Pro 的骨架环合 


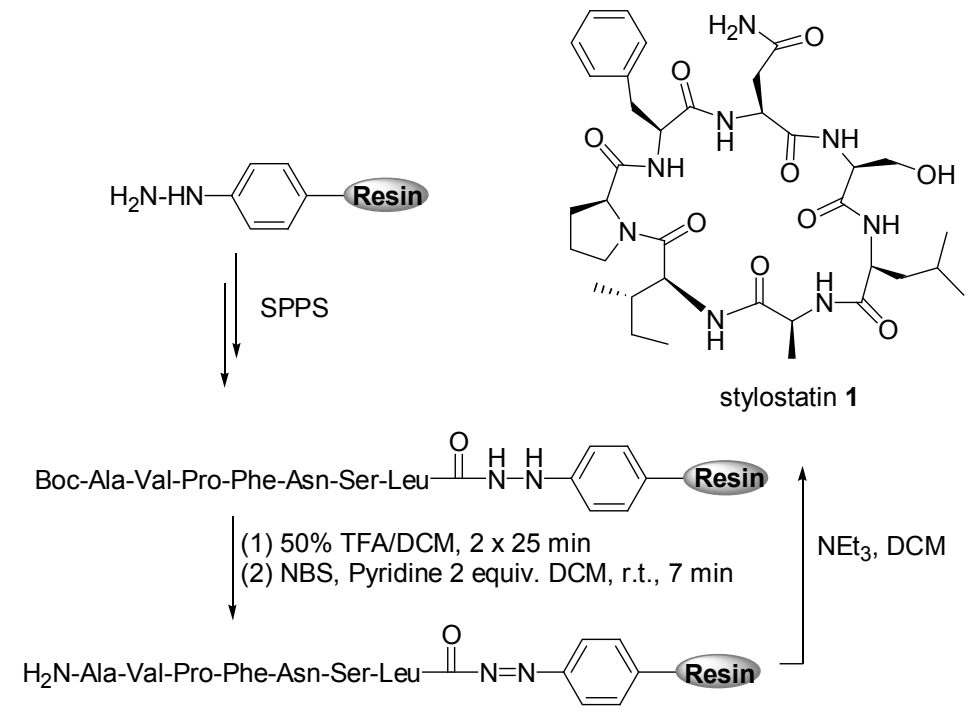

图 3 芳基酰基肼树脂用于多肽骨架环化反应

Figure 3 On-resin cyclization of peptide anchored to resin with an aryl hydrazine linker at C-termini

反应 ${ }^{[33]}$. 随着肽链对接技术的发展, 化学选择性反应成 为骨架环肽合成的新兴方法. 相比传统缩合反应, 化学 选择性反应立体保持性高, 反应条件更为温和和高效, 因而成为该方面近期研究的主流.

\section{1 构象锁定结构辅助骨架环化反应}

线性多肽在溶液中一般没有结构, 导致其 $\mathrm{C}$ 端和 $\mathrm{N}$ 端碰撞的几率不高, 因而分子内环化反应速率相对较 慢. 为了提高分子内骨架环化反应的效率, 研究者可以 将线性多肽的构象限制于环化易发生的构象. 限制线性 多肽构象的方法一般有两种, 即内部引入可改造多肽结 构的保护基或外加可促进特定构象形成的金属离子.

噟脯氨酸结构单元引入多肽序列可达到限制线性 多肽构象促进分子内头尾环化反应的效果. 丙叉保护的 Ser, Thr 或 Cys 是常见的三种噟脯氨酸, 且均可通过酸 性条件脱去保护基得到天然结构的氨基酸. 1999 年, Mutter 等 ${ }^{[34]}$ 将噟脯氨酸作为 $\mathrm{Thr}$ 的前体成功实现了骨架 环三肽的合成, 并证明环化底物线性多肽的浓度可高达 $0.1 \mathrm{~mol} / \mathrm{L} .2004$ 年, Turner 等 ${ }^{[35]}$ 引 3 对丙叉保护 Thr 辅助分子内环化, 实现骨架环六肽 $\left[(\mathrm{Val}-\mathrm{Thr})_{3}\right]$ 的合成, 如图 4 所示. 2010 年, Jolliffe 等 ${ }^{[36]}$ 报道了该方法在骨架 环四肽合成方面的应用.

金属离子通过与多肽序列中的基团配位作用可以 促进线性多肽头尾空间接近从而利于分子内环化反应 的发生. 2003 年, $\mathrm{Ye}$ 等 ${ }^{[37]}$ 发现 $\mathrm{Na}^{+}$可以与多肽中 5 个邻 近的羰基发生络合促进骨架环五肽的合成, 如图 4 所示. 该研究组 ${ }^{[38]}$ 在 2005 年发现 $\mathrm{Cs}^{+}$也能通过类似的机制促 进骨架环七肽的合成.

\subsection{Sanger 试剂、Mukaiyama 试剂或者 $\mathrm{N}$ 端缺电子 基团取代的磺胺试剂活化 C 端巯基酸肽环化反应}

$\mathrm{C}$ 端巯基酸肽可以与 Sanger 试剂、Mukaiyama 试剂 或者 $\mathrm{N}$ 端缺电子基团取代的磺胺试剂反应转变为活性 较高的 $\mathrm{C}$ 端芳基硫酯肽. $\mathrm{N}$ 端自由的氨基可以与芳基硫 酯肽发生分子内环化反应生成骨架环肽. 2010 年, Crich 等 ${ }^{[39-41]}$ 采用 Sanger 试剂活化 C 端颈基酸肽成功合成了 骨架环五肽和骨架环六肽, 如图 5 所示. 侧链官能团因 影响该反应过程一般采用酸敏感基团进行保护，在环化 反应完成后，保护基可以在酸性下解保护得到天然结构 的骨架环肽.

\section{3 金属离子或有机碱催化硫酯肽骨架环化反应}

早在上个世纪 80 年代, 日本科学家 Aimoto 等 ${ }^{[42]}$ 发 现，在金属离子 $\mathrm{Ag}^{+}$的催化下, 多肽硫酯可以与多肽的 氨基发生高效的连接反应. 亲硫性金属离子 $\mathrm{Ag}^{+}$通过与 $\mathrm{C}$ 端硫酯配位加强了硫酯的离去性, 从而促进自由氨基 与其发生胺解反应.

1999 年, $\mathrm{Tam}$ 等 ${ }^{[43]}$ 采用 $\mathrm{Ag}^{+}$催化多肽 $\mathrm{N}$ 端氨基与 $\mathrm{C}$ 端硫酯的分子内环化反应, 完成了骨架环七肽 [AIa-Lys-Tyr-GIy-GIy-Phe-Leu]的化学合成. 有趣的是, Tam 研究表明, 通过调节溶液的酸度, $\mathrm{Ag}^{+}$催化硫酯可 选择性与 $\mathrm{N}$ 端氨基、 Lys 侧链氨基或 Tyr 侧链酚羟基发 生反应, 如图 6 所示. 在 $\mathrm{pH} 4.0$ 的溶液中, Lys 侧链氨基 和 $\mathrm{N}$ 端氨基均被质子化而失去反应活性，Tyr 侧链酚羟 基优先与 $\mathrm{C}$ 端硫酯发生分子内环化生成大环内酯肽; 在 $\mathrm{pH} 5.0 \sim 6.0$ 时, $\mathrm{N}$ 端氨基和 $\mathrm{C}$ 端硫酯优先发生环化反应, 生成传统的骨架环多肽; 在 $\mathrm{pH}>6$ 时, Lys 侧链氨基活 
(a)

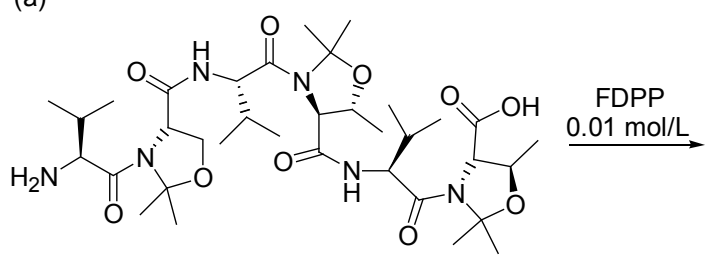<smiles>CC(C)C1NC(=O)C2C(C)OC(C)(C)N2C(=O)[C@@H]2[C@@H](C)OC(C)(C)N2C(=O)C(C(C)C)NC(=O)C2[C@@H](C)OC(C)(C)N2C(=O)C2NC(=O)C(C(C)C)N2C1=O</smiles>

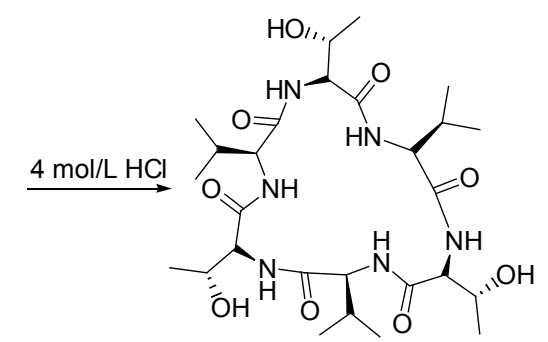

(b)<smiles>[R]C([NH])C(=O)NC([R])C(=O)NC([R])C(=O)NC([R])C(=O)NC([R])C(=O)O[NH2+]</smiles>

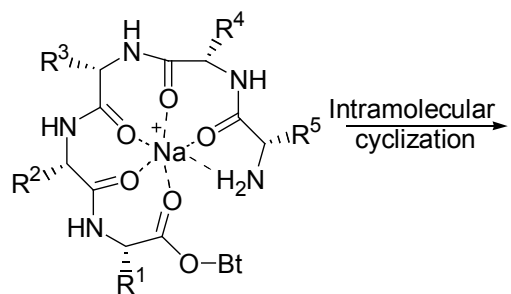<smiles>[R2]C1NC(=O)C([R])NC(=O)[C@H]([R])NC(=O)[C@H]([R7])NC(=O)C([R])NC1=O</smiles>

图 4 构象锁定结构辅助多肽骨架环化

Figure 4 Conformational control to assist peptide cyclization (a) Pseudoproline derived from $L$-threonine; (b) sodium ions assistance

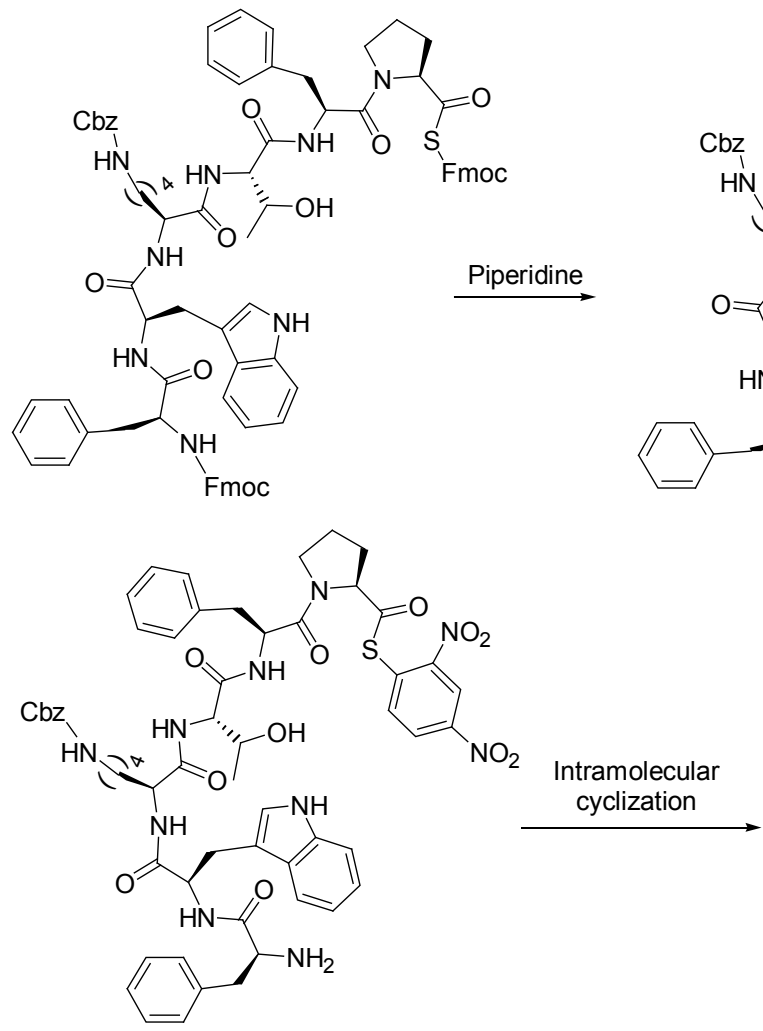

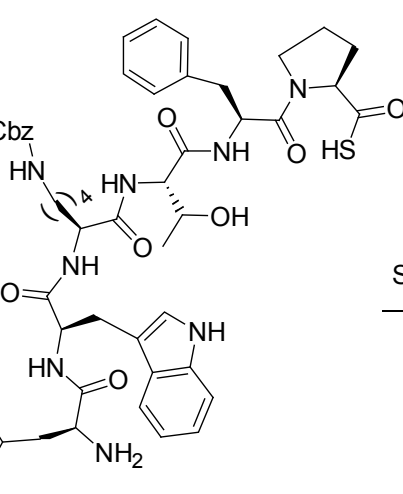

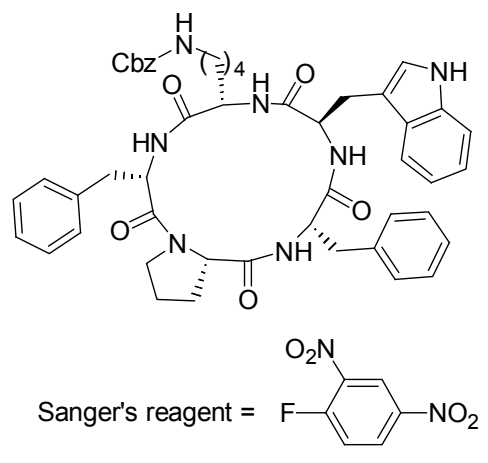

图 5 Sanger 试剂辅助分子内骨架环化反应

Figure 5 Intramolecular condensation reaction mediated by Sanger reagent

性最高, 最利于发生分子内环化反应产生侧链环肽结 构. 需指出, $\mathrm{Ag}^{+}$催化硫酯的过程并不总能保持反应位 点手性中心的构型, 尤其对于反应速率较为缓慢的环化 过程.

在咪唑的催化下, 硫酯也能被活化而与氨基发生分
子内环化反应. 2009 年, Houghten 等 ${ }^{[44]}$ 利用含有咪唑的 乙腈溶液( $\mathrm{MeCN} ： 1.5 \mathrm{~mol} / \mathrm{L}$ 咪唑)成功合成了骨架环五 肽. 最近, Houghten 等 ${ }^{[45]}$ 又发现, 在咪唑催化下丝氨酸 侧链羟基也能与硫酯发生分子内酯化反应，可用于化学 合成天然产物大环内酯肽. 


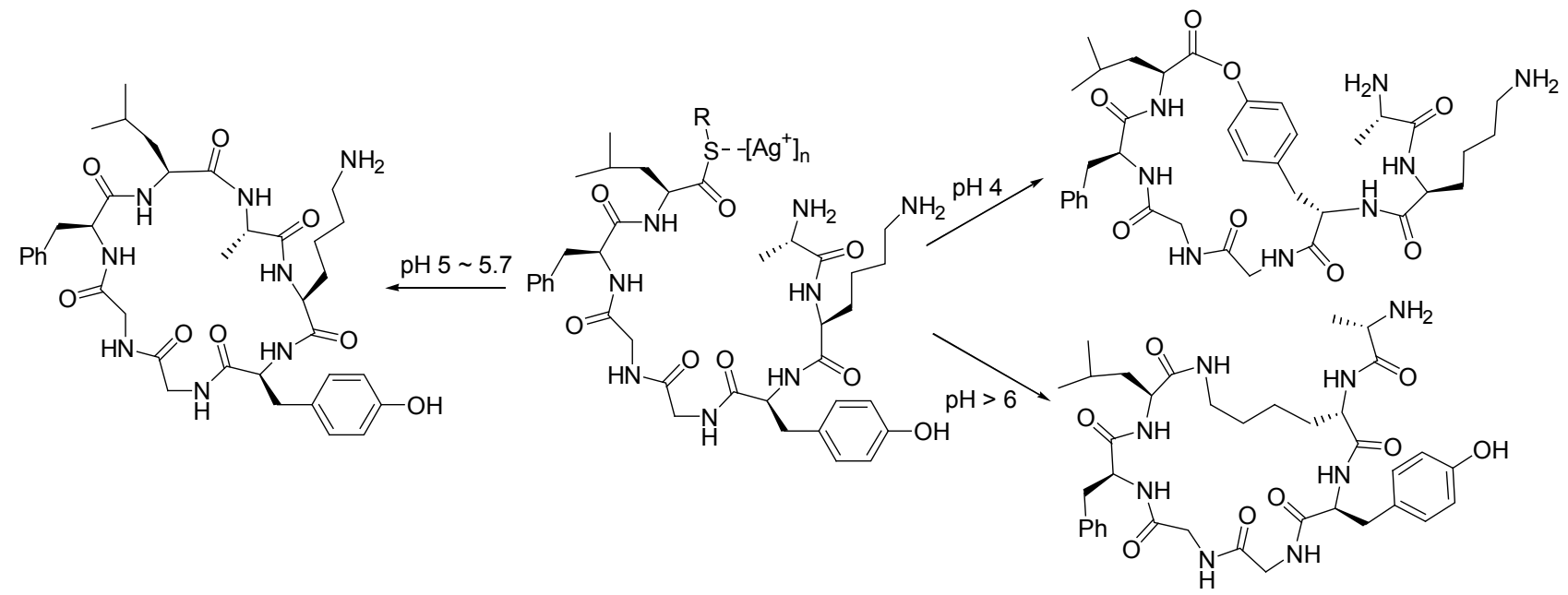

图 6 银离子辅助多肽环化反应

Figure 6 Silve(I) mediated macrocyclization of peptides

\section{4 无痕施陶丁格骨架环化反应}

2000 年, Raines ${ }^{[46]}$ 和 Bertozzi 等 ${ }^{[47]}$ 相继发展出无痕 施陶丁格连接反应. 该反应是施陶丁格反应的改进. 具 体机制为, 首先含有机磷和硫酯修饰的多肽会与叠氮修 饰另一分子多肽反应生成多肽磷叶立德中间产物, 接下 来叶立德中的亲核性胺通过分子内 $\mathrm{N}$ 到 $\mathrm{S}$ 迁移形成酰胺 键, 最后磷基和颈基修饰基团在水中发生水解反应而离 去完成多肽片段的无痕连接.

2008 年, Hackenberger 等 ${ }^{[48]}$ 将无痕施陶丁格连接反 应用于分子内反应, 完成了三种骨架环十一肽的化学合 成. 该研究表明无痕施陶丁格环化反应既可用于侧链保 护肽的头尾环化又可用于侧链不保护多肽的头尾选择 性环化. 侧链保护肽的头尾环化是采用嗍试剂保护有机 磷，用 DABCO (1,4-二氮杂二环[2.2.2]辛烷)选择性解 除硼基保护基, 释放 $\mathrm{C}$ 端磷基修饰硫酯肽用于分子内环 化, 如图 7 所示. 酸性条件解除侧链所有保护基得到的

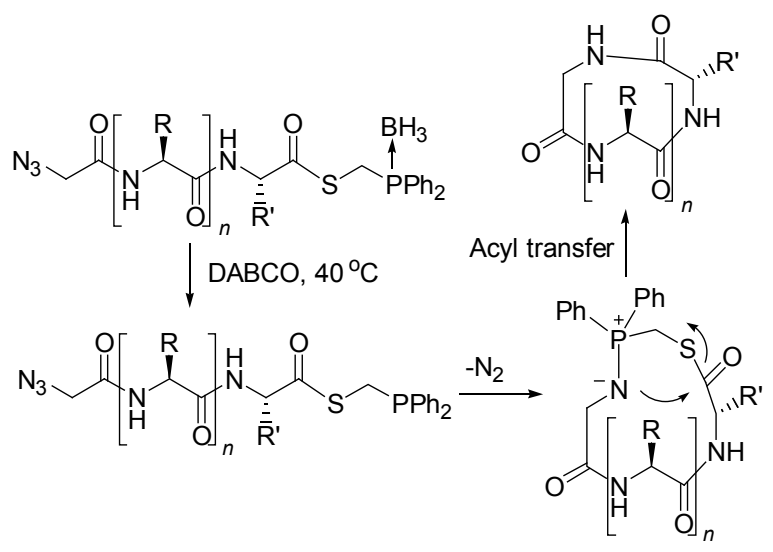

图 7 无痕施陶丁格用于多肽骨架环化反应

Figure 7 Peptide cyclization by traceless Staudinger ligation
$\mathrm{C}$ 端为磷修饰硫酯和 $\mathrm{N}$ 端为叠氮修饰肽可直接经过分子 内环化反应产生天然骨架环肽. 需指出, 无痕施陶丁格 环化连接存在几个缺点. 例如, 反应底物磷试剂易于被 氧气氧化; 反应中需加有机溶剂以抑制水解副反应; 环 化反应位点一般为位阻较低的 Gly.

\section{5 醛基氧酯与 Ser/Thr 骨架环化反应}

早在 1994 年, $\mathrm{Tam}$ 等 ${ }^{[49]}$ 发现 $\mathrm{C}$ 端为 $\beta$-差基乙醛修 饰的氧酯肽可以选择性与 $\mathrm{N}$ 端 Ser, Thr 或 Cys 发生化学 选择性成酰胺键连接反应. 为解决 Tam 方法中反应转 化速率低和修饰基团不易解除的缺点, 2010 年, $\mathrm{Li}$ 等 ${ }^{[50]}$ 将邻羟基苯甲醛替代 $\beta$-羟基乙醛, 发展出新一代以 Ser 和 Thr 为连接位点的化学选择性连接反应, 如图 8 所示. 相比而言, 该反应效率显著提高, 并可用于 $\mathrm{C}$ 端为高位 阻的 Val 的连接. 因为结构中的辅助基团可以在 TFA 中 高效去除，所以该反应得到的产物为天然结构的骨架环

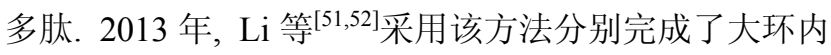
酯肽一达托霉素和骨架环四肽的合成. 然而, 该反应中 所需 $\mathrm{C}$ 端氧酯肽的合成操作相对较为复杂, 且反应需在 吡啶乙酸的混合溶剂中进行 ${ }^{[51]}$.

\section{6 酮酸-羟胺环化反应}

2006 年, Bode 等 ${ }^{[53]}$ 发现 $\mathrm{C}$ 端酮酸修饰多肽可以与 $\mathrm{N}$ 端差胺化修饰的多肽发生高效选择性成酰胺键反应. 该 反应的基本原理是羟胺与酮酸通过分子内脱羧和脱水 反应形成天然酰胺键. 2012 年, Bode 等 ${ }^{[54]}$ 运用分子内的 酥酸一羟胺反应成功完成了环 10 肽一短杆菌肽的化学合 成, 如图 9. 需指出, 该反应一般要求在还有 DMF 的有 机溶剂中进行, 且反应温度在 $40{ }^{\circ} \mathrm{C}$ 左右时反应速率较 为高效. 


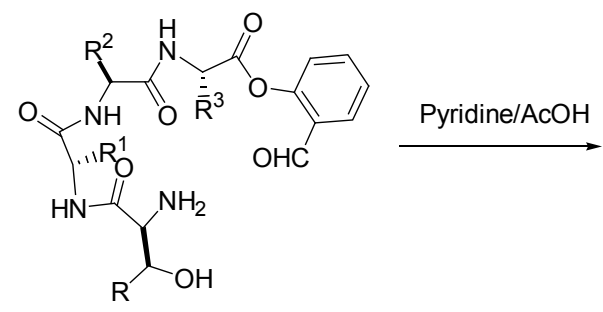<smiles>[R]C(NC(=O)C([R])NC1NC(c2ccccc2OC)OC1[R])C(=O)NC([R])C(=O)NC([R])[N+](=O)[O-]</smiles><smiles>[R]C(NC(=O)C1C([R])OC(c2ccccc2O)N1C(=O)C([R])N[I+](C)(C)C)C(=O)NC([R])C([R])N</smiles><smiles>[R]C(O)C(=O)NC([R])C(=O)NC([R])C(=O)NC([R])C(=O)NC([R])C([R])O</smiles>

图 $8 \mathrm{Ser} / \mathrm{Thr}$ 连接反应用于多肽骨架环化反应

Figure 8 Peptide cyclization by Ser/Thr ligation

\section{3 自然化学连接策略}

1994 年, Kent 等 ${ }^{[55 ~ 61]}$ 发展的自然化学连接反应是 应用最为广泛的蛋白质的化学合成方法. 即在 $\mathrm{pH}$ 为 7 和硫醇存在下, 一分子 $\mathrm{C}$ 端为硫酯的肽链与另一条 $\mathrm{N}$ 端 为半胱氨酸的肽可以发生高效的成酰胺键连接反应. 自 然化学连接反应经过化学选择性捕获和分子内重排两 个步骤而完成. 首先, 两分子的 C 端硫酯和 $\mathrm{N}$ 端 Cys 侧 链放基之间发生可逆的硫醇一硫酯交换生成一分子的硫 酯中间体，其次，通过分子内不可逆的 $\mathrm{S}-\mathrm{N}$ 酰基迁移， 生成天然肽键. 自然化学连接反应的优点是: 高效、高 选择性、侧链完全无需保护。骨架环肽可以通过分子内 的自然化学连接反应制备, 即一条同时含有 C 端硫酯和 $\mathrm{N}$ 端 Cys 的线性肽可以通过分子内的成酰胺键反应实现 头尾连接, 如图 10 所示. 1997 年, Tam 等 ${ }^{[62]}$ 首次用分子 内自然化学连接反应合成了植物环多肽 Cyclotide. 随 后, 许多研究者均采用自然化学连接反应完成了骨架环 肽的合成. 原则上，自然化学连接环合策略属于液相环

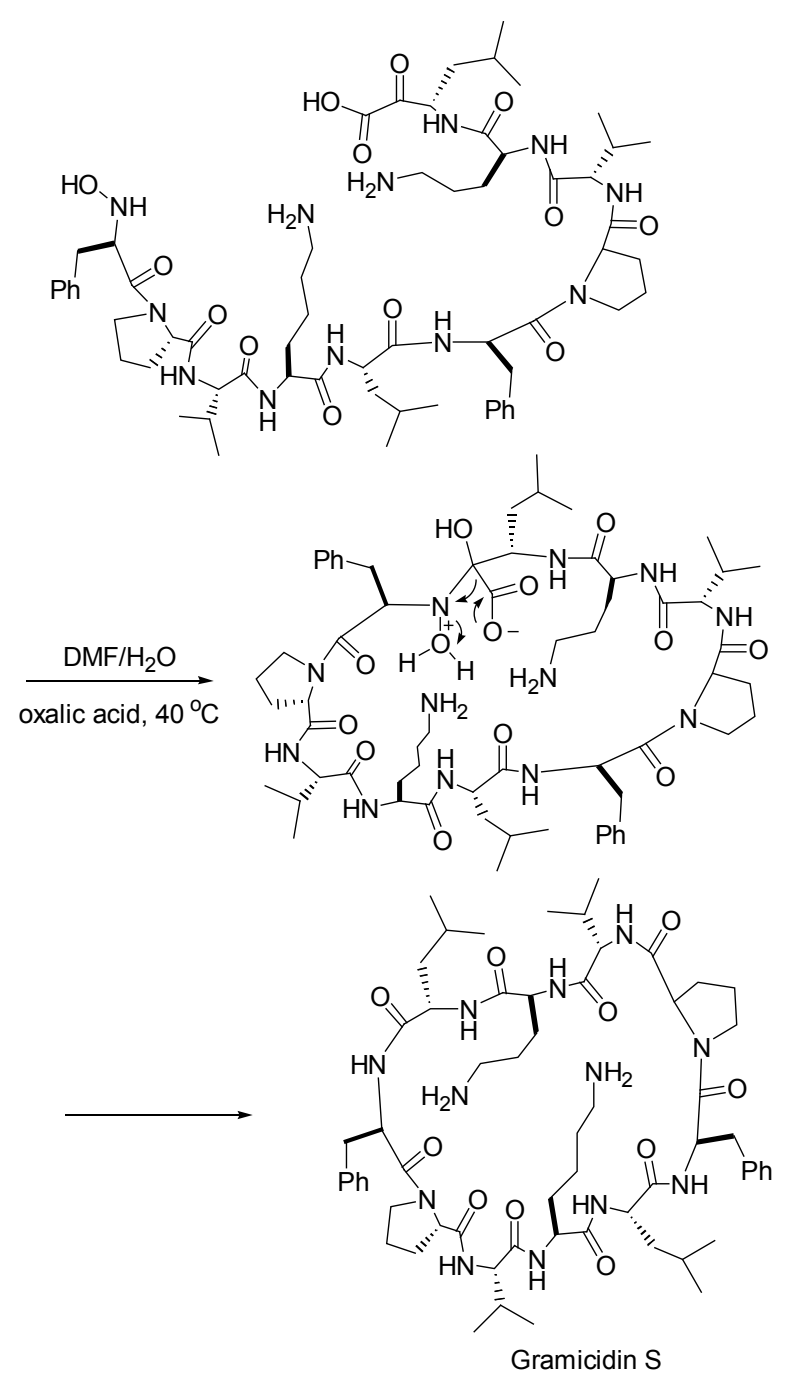

图 $9 N$-烷基化羟基胺与 $\alpha$-酮酸脱羧偶联反应用于多肽环化

Figure 9 Peptide cyclization by decarboxylative condensations between $N$-alkylhydroxylamines and $\alpha$-ketoacids

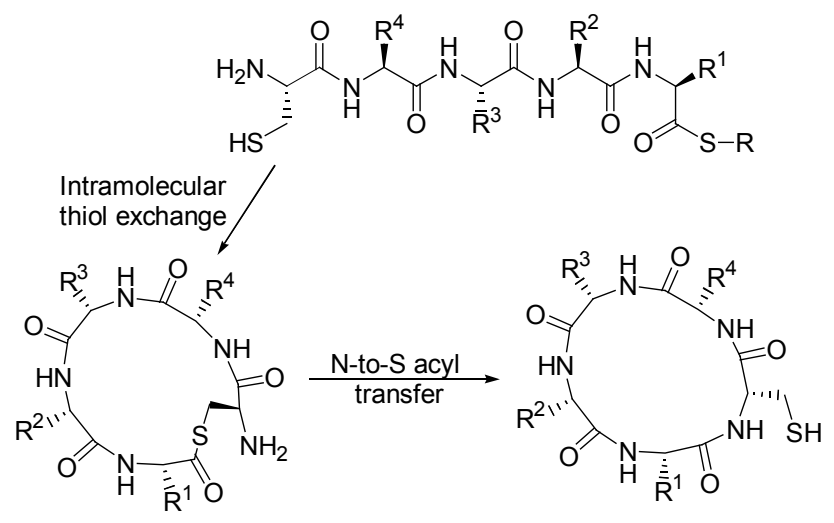

图 10 分子内自然化学连接反应

Figure 10 Intramolecular native chemical ligation 化反应的一种. 基于该方面的研究较多, 我们对其专门 的介绍. 


\section{1 分子内巯基拉链式自然化学骨架环化反应}

分子内統基拉链骨架环化反应是指富含半胱氨酸 的肽通过分子内颈基-硫酯交换反应，促进多肽 $\mathrm{C}$ 端硫 酯与 $\mathrm{N}$ 端 $\mathrm{Cys}$ 空间接近而完成分子内自然化学连接反 应, 如图 11. 这种反应方法需要 3 种重要官能团: $\mathrm{N}$ 端 Cys、C 端硫酯和内部自由統基. 首先, 离 $\mathrm{C}$ 端硫酯近 的半胱氨酸侧链亲核性进攻硫酯, 即硫醇一硫酯交换形 成分子内硫酯; 其次, 通过分子内可逆的转硫酯化过程, 形成更大的分子内硫酯, 使得 $\mathrm{C}$ 端和 $\mathrm{N}$ 端进一步接近; 最终, 通过不可逆的 $\mathrm{S}-\mathrm{N}$ 酰基转移反应形成内酰胺. 1999 年, Tam 等 ${ }^{[63]}$ 首次提出了分子内颈基拉链环化反应 机理, 并指出拉链环化反应是熵驱动的过程, 即通过小 的离散中间产物使得反应比相应的一步环合反应更高 效. 尽管研究证明分子内部自由硫醇可以加快分子内的 自然化学反应速率, 但是并不能确定转硫酯化一定沿着 链相继地发生, 同时也不能确定所有的自由硫醇都参与 催化过程 ${ }^{[64]}$.

\subsection{C 端巯基修饰芳基氧酯肽参与自然化学骨架环化} 反应

2004 年, Danishefsky 等 ${ }^{[65]}$ 发现 C 端含有邻巯基修饰
的芳基氧酯肽可以通过 $\mathrm{O}$ 到 $\mathrm{S}$ 分子内酰基迁移原位生成 硫酯肽, 实现与 $\mathrm{N}$ 端 $\mathrm{Cys}$ 肽的化学选择性连接反应. 利 用芳基氧酯肽作为硫酯肽的前体和分子内自然化学连 接反应, Danishefsky 等 ${ }^{[6]}$ 于 2006 年实现了含有单糖修 饰的骨架环六肽的化学合成, 如图 12 所示.

\section{$3.3 \mathrm{C}$ 端颈基修饰烷基氧酯肽参与自然化学骨架环化 反应}

硫酯键对碱和亲核试剂非常不稳定，易于和哌啶发 生反应, 因而, 不能直接采用 Fmoc 法固相合成, 而只能 采用 Boc 法进行制备. 传统的 Boc-SPPS 制备硫酯中需 要使用极为危险的 HF，且带有多种翻译后修饰肽的对 $\mathrm{HF}$ 均不稳定, 如糖修饰和磷酸化修饰等. 为解决这一 问题, 近年来要发展了多种有效的 Fmoc-SPPS 合成多 肽硫酯的方法. O-S 迁移硫酯制备法是 Fmoc 法制备硫 酯肽的一种重要方法. 该方法利用烷基氧酯作为硫酯的 前体，通过分子内 $\mathrm{O}-\mathrm{S}$ 迁移原位形成硫酯用于自然化 学连接反应 ${ }^{[67 ~ 69]} .2012$ 年, Liu 等 ${ }^{[70]}$ 采用氧酯肽, 通过分 子内的自然化学连接反应完成了植物骨架环多肽 KB1 的合成, 如图 13 所示. 氧酯与 Fmoc 固相合成兼容, 因
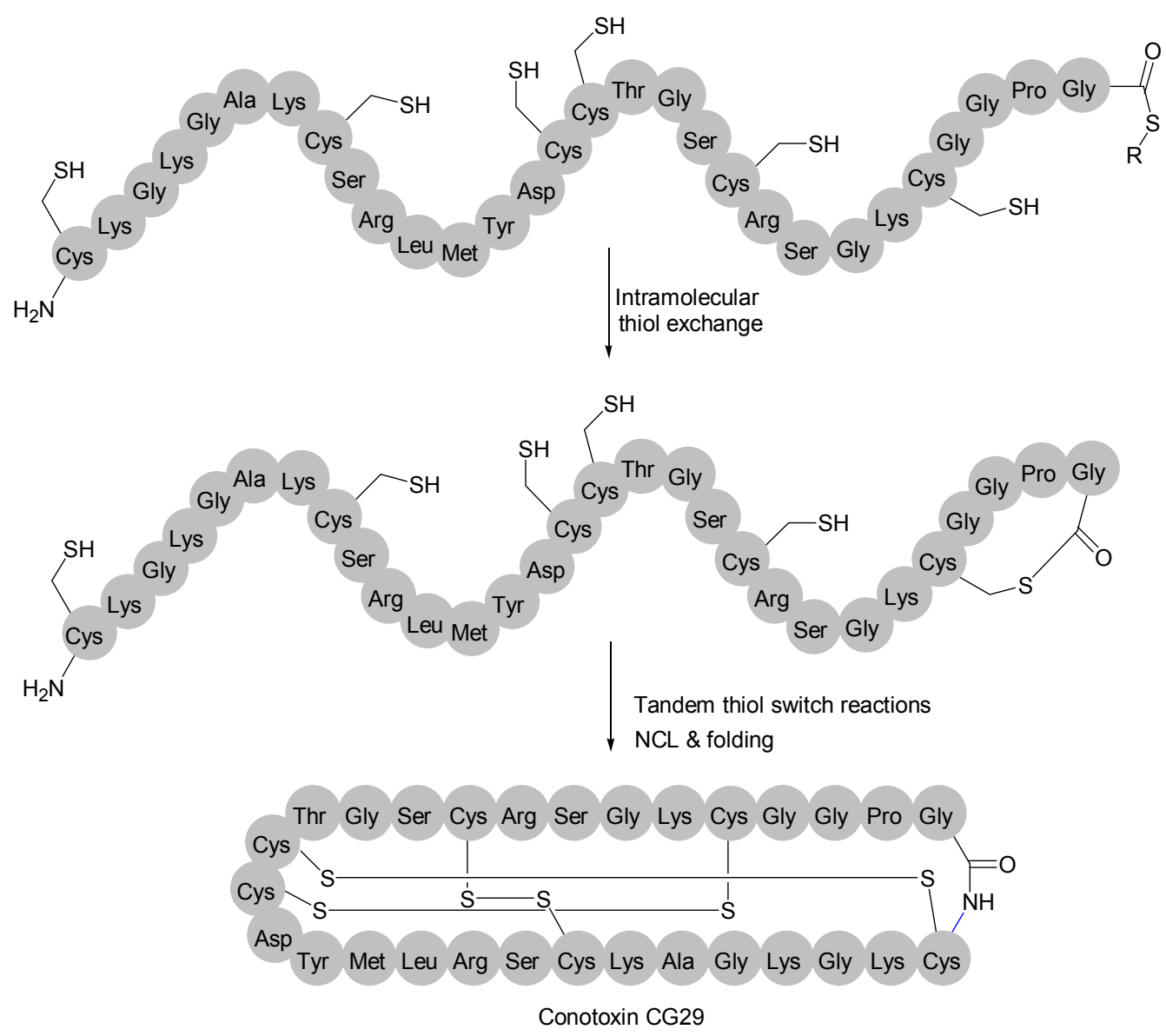

图 11 颈基拉链式自然化学环化反应

Figure 11 Thia zip reaction for cyclic peptides synthesis 

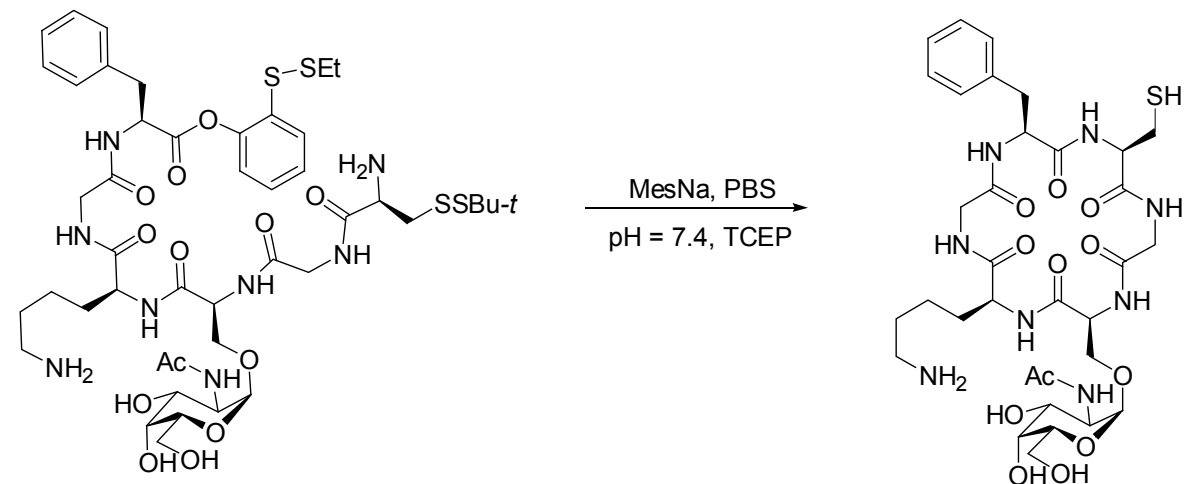

图 12 颈基酚酯肽参与的分子内自然化学连接反应

Figure 12 Intramolecular native chemical ligation by using peptide ortho-thiophenolic ester
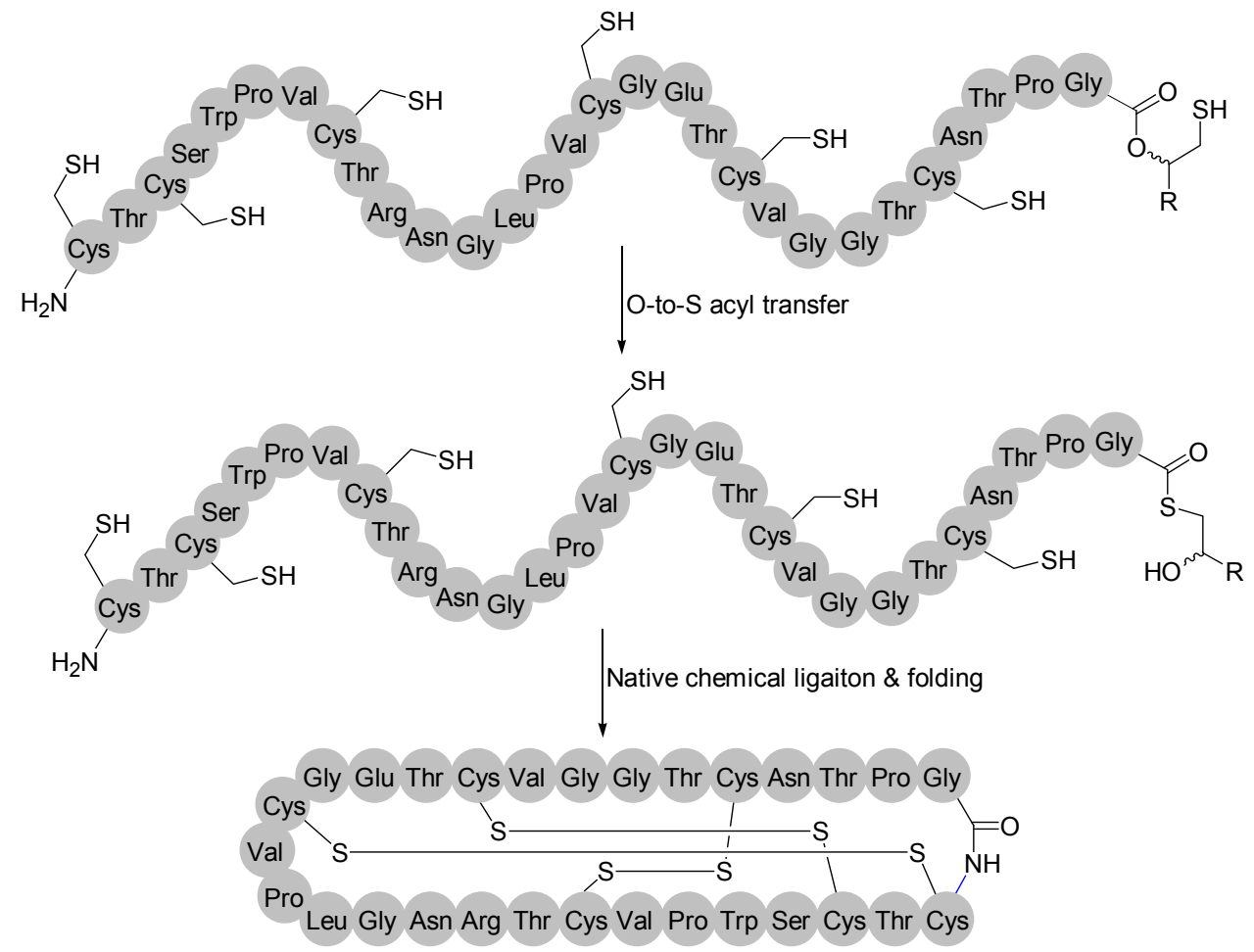

Cyclotide KB1

图 13 烷基氧酯肽参与的分子内自然化学连接反应

Figure 13 Intramolecular native chemical ligation by using Peptide O-ester

而制备起来比硫酯更为方便. 然而需注意, $\mathrm{O}-\mathrm{S}$ 迁移仅 仅适用于位阻较小的氨基酸，对于高位阻的环化反应， 存在水解副反应.

\subsection{C 端巯基修饰酰胺肽参与的自然化学骨架环化反}

\section{应}

与氧酯肽类似，研究者发现多种 $\mathrm{C}$ 端含颈基修饰的 酰胺肽也可作为硫酯肽的前体. 2011 年, Macmillan 等 ${ }^{[71]}$ 以 $\mathrm{C}$ 端为二肽 Gly-Cys、 $\mathrm{N}$ 端为 Cys 的天然线性多肽为 底物, 利用二肽 Gly-Cys 的分子内的 N-S 迁移硫酯化机
制，完成了多种抗菌骨架环多肽的合成. 2013 年，Tam 等 ${ }^{[72]}$ 以 $\mathrm{C}$ 端为 $N$-颈乙基- $N$-烷基化酰胺多肽为底物, 利 用 $N$-烷基化酰胺易于发生分子内的 N-S 迁移的特征, 完 成了植物骨架环多肽 Kalata B1 的合成. 与氧酯相似, C 端酰胺肽对于位阻较高的环化反应较差.

\subsection{C 端酰肼肽参与的自然化学骨架环化反应}

虽然国际上有很多课题组发展了一系列有效的 Fmoc-SPPS 间接合成多肽硫酯的方法, 但是均存在问 题, 如需要预制结构复杂的连接臂、成硫酯反应受位阻 
影响大和底物反应活性不宜控制等. 2011 年, Liu 等 ${ }^{[73 \sim 78]}$ 以酰肼多肽作为底物, 发展出酰肼连接技术, 解 决了前人方法的问题, 成为多肽及蛋白合成方面的一个 重要成果.

酰肼连接技术的基本原理是, 在弱酸条件下, 多肽 酰肼在亚硝酸的氧化下转化为酰基叠氮, 随后与硫醇反 应原位生成肽硫酯并直接与 $\mathrm{N}$ 端 Cys 肽自然化学选择性 连接反应. 本质上来说, 这种连接方法是酰肼和硫酯原 位转变, 是一种改进的自然化学连接反应. 多肽酰肼也 可以通过生物表达进行制备. 2012 年, Liu 等 ${ }^{[79]}$ 采用非天 然氧酯氨基酸嵌入技术成功表达出多肽酰肼, 发展了表 达蛋白酰肼连接技术. 同年, Liu 课题组 ${ }^{[80]}$ 运用分子内 酰肼连接反应, 成功制备了系列大小的骨架环多肽, 如 图 14 所示. 值得注意, Liu 等 ${ }^{[81]}$ 证明分子内酰肼反应可 以用于高效制备张力较大的骨架环四肽. 相比前人方 法, 多肽酰肼具有合成难度低、成本低廉、自动化简便 的优势. 此外, 酰肼连接技术的连接效率不受位阻影响, 对于绝大多数位点的连接均适用.

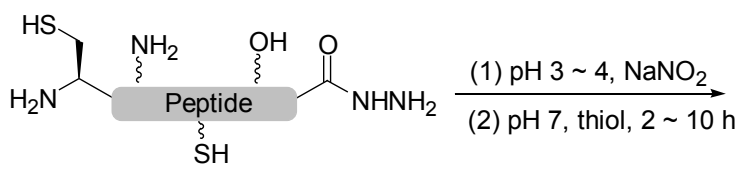<smiles>NCCC(S)CS</smiles>

图 14 酰朋肽参与的分子内自然化学连接反应 Figure 14 Intramolecular native chemical ligation by using peptide hydrazides

\section{4 前景和展望}

20 世纪 40 年代, 高斯等发现著名的治疗伤口感染 的短杆菌肽, 让研究者开始关注骨架环多肽研究. 在过 去的将近七十年里, 科学家在细菌、真菌、植物和动物 中均发现骨架环肽, 并有少数骨架环肽已成为治疗人类 疾病的药物分子. 最近, 研究者发展出功能药物多肽 “嫁接” Cyclotide 技术, 为骨架环肽药物研发提供了一 条强有力的工具. 2012 年, Tam 等 ${ }^{[82}$ 将舒缓激肽 B1 受体 怙抗肽嫁接到 Cyclotide 骨架内, 开发出治疗疼痛的可 口服的多肽药物分子. 2013 年, Camareo 等 ${ }^{[83]}$ 运用生物 方法将生物活性短肽 PMI 嫁接到 Cyclotide, 并在小鼠体 内确认该环肽能够通过激活 P53 蛋白来抑制肿瘤生长. 在这几十年里, 化学研究者也发展了多种骨架环肽合成 的方法. 从固相环化反应到液相环化反应, 从传统缩合 剂缩合反应到近期发展的化学选择性连接反应, 化学方
法已经逐渐成为制备骨架环肽的重要手段. 随着骨架环 肽合成技术的成熟和其结构与功能方面的深入研究，我 们相信将有更多的骨架环肽药物分子被人们发现.

\section{References}

[1] Scott, C. P.; Santos, E. A.; Wahnon, D. C.; Benkovic, S. J. Proc. Natl. Acad. Sci. U. S. A. 1999, 96, 13638.

[2] Kohli, R. M.; Walsh, C. T.; Burkart, M. D. Nature 2002, 418, 658.

[3] Tam, J. P.; Wong, C. T. T. J. Biol. Chem. 2012, 287, 27020.

[4] Morimoto, J.; Hayashi, Y.; Suga, H. Angew. Chem., Int. Ed. 2012, $51,3423$.

[5] Verdine, G. L.; Walensky, L. D. Clin. Cancer Res. 2007, 13, 7264.

[6] Pattabiraman, V. R.; Bode, J. W. Nature 2011, 480, 471.

[7] Cui, H.-K.; Guo, Y.; He, Y.; Wang, F.-L.; Chang, H.-N.; Wang, Y.-J.; Wu, F.-M.; Tian, C.-L.; Liu, L. Angew. Chem., Int. Ed. 2013 $52,9558$.

[8] Gause, G. F.; Brazhnikova, M. G. Nature 1944, 154, 703.

[9] Henriques, S. T.; Clark, D. T. Drug Discovery Today 2010, 15, 57.

[10] Camarero, J. A. Proc. Natl. Acad. Sci. U. S. A. 2011, 108, 10025.

[11] Chin, J. W.; Schepartz, A. J. Am. Chem. Soc. 2001, 123, 2929.

[12] Davies, J. S. J. Pept. Sci. 2003, 9, 1502.

[13] Parenty, A.; Moreau, X.; Campagne, J. M. Chem. Rev. 2006, 106, 911.

[14] Jiang, S.; Li, Z.; Ding, K.; Roller, P. Curr. Org. Chem. 2008, 12, 1502.

[15] Clark, R. J.; Craik, D. J. Biopolymers 2010, 94, 414.

[16] White, C. J.; Yudin, A. K. Nat. Chem. 2011, 3, 509.

[17] Wang, D. X.; Hang, X.; Gong, X.; Feng, H. H. Chin. J. Org. Chem. 2008, 28, 549.

[18] Alcaro, M. C.; Sabatino, G.; Uziel, J.; Chelli, M.; Ginanneschi, M.; Rovero, P.; Papini, A. M. J. Pept. Sci. 2004, 10, 218.

[19] Sabatino, G.; Chelli, M.; Mazzucco, S.; Ginanneschi, M.; Papini, A. M. Tetrahedron Lett. 1999, 40, 809.

[20] Alsina, J.; Rabanal, F.; Giralt, E.; Albericio, F. Tetrahedron Lett. 1994, 35, 9633.

[21] Bolscher, J. G. M.; Oudhoff, M. J.; Nazmi, K.; Antos, J. M.; Guimaraes, C. P.; Spooner, E.; Haney, E. F.; Vallejo, J. J. G.; Vogel, H. J.; Hof, W. V.; Ploegh, H. L.; Veerman, E. C. I. FASEB J. 2011, 25, 2650.

[22] Yang, L.; Morriello, G. Tetrahedron Lett. 1999, 40, 8197.

[23] Bourel-Bonnet, L.; Rao, K. V.; Hamann, M, T.; Ganesan, A. J. Med. Chem. 2005, 48, 1330.

[24] de Visser, P. C.; Kriek, N. M.; van Hooft, P. A.; Filippov, D. V.; van der Marel, G. A.; Overkleeft, H. S.; van Boom, J. H.; Noort, D. J. J. Pept. Res. 2003, 61, 298.

[25] Mukhtar, T. A.; Koteva, K. P.; Wright, G. D. Chem. Biol. 2005, 12, 229.

[26] Ali, L.; Musharraf, S. G.; Shaheen, F. J. Nat. Prod. 2008, 71, 1059.

[27] Wieland, T.; Lewalter, J.; Birr, C. Liebigs Ann. Chem. 1970, 31, 740.

[28] Schmidt, U.; Langner, J. J. Pept. Res. 1997, 49, 67.

[29] Rosenbaum, C.; Waldmann, H. Tetrahedron Lett. 2001, 42, 5677.

[30] Shigenaga, A.; Moss, J. A.; Ashley, F. T.; Kaufmann, G. F.; Janda, K. D. Synlett 2006, 551.

[31] Camarero, J. A.; Hackel, B. J.; de Yoreo, J. J.; Mitchell, A. R. J. Org. Chem. 2004, 69, 4145.

[32] Aboye, T. L.; Li, Y.-L.; Majumder, S.; Hao, J.-F.; Alexander Shekhtman, J. A. Camarero, J. A. Bioorg. Med. Chem. Lett. 2012, $22,2823$.

[33] Heinlein, C.; Silva, D. V.; Troster, A.; Schmidt, J.; Gross, A.; Un- 
verzagt, C. Angew. Chem., Int. Ed. 2011, 50, 6406.

[34] Rückle, T.; de Lavallaz, P.; Keller, M.; Dumy, P.; Mutter, M. Tetrahedron 1999, 55, 11281.

[35] Skropeta, D.; Jolliffe, K. A.; Turner, P. J. Org. Chem. 2004, 69, 8804 .

[36] Fairweather, K. A.; Sayyadi, N.; Luck, I. J.; Clegg, J. K.; Jolliffe, K. A. Org. Lett. 2010, 12, 3136

[37] Ye, Y.-H.; Gao, X.-M.; Liu, M.; Tang, Y.-C; Tian, G.-L. Lett. Pept. Sci. 2003, 10, 571 .

[38] Liu, M.; Tang, Y. C.; Fan, K. Q.; Jiang, X.; Lai, L. H.; Ye, Y. H. J. Pept. Res. 2005, 65, 55.

[39] Sasaki, K.; Crich, D. Org Lett. 2010, 12, 3254.

[40] Crich, D.; Sharma, I. Angew. Chem., Int. Ed. 2009, 48, 7591.

[41] Crich, D.; Sharma, I. Angew. Chem., Int. Ed. 2009, 48, 2355.

[42] Aimoto, S.; Mizoguchi, N.; Hojo, H.; Yoshimura, S. Bull. Chem. Soc. Jpn. 1989, 62, 524.

[43] Zhang, L.-S.; Tam, J. P. Tetrahedron Lett. 1997, 38, 4575.

[44] Li, Y.; Yongye, A.; Giulianotti, M.; Martinez-Mayorga, K.; Yu, Y.; Houghten, R. A. J. Comb. Chem. 2009, 11, 1066.

[45] Li, Y.; Giulionatti, M.; Houghten, R. A. Org. Lett. 2010, 12, 2250.

[46] Nilsson, B. L.; Kiessling, L. L.; Raines, T. R. Org. Lett. 2000, 2, 1939.

[47] Saxon, E. J. I.; Armstrong, J. I.; Bertozzi, C. R. Org. Lett. 2000, 2, 2141.

[48] Kleineweischede, R.; Hackenberger, C. P. R. Angew. Chem., Int. Ed. 2008, 47, 5984.

[49] Liu, C.-F.; Tam, J. P. Proc. Natl. Acad. Sci. U. S. A. 1994, 91, 6584.

[50] Li, X.-C.; Lam, H.-Y.; Zhang, Y.-F.; Chan, C.-K. Org. Lett. 2010, 12, 1724.

[51] Lam, H.-Y.; Zhang, Y.-F.; Liu, H.; Xu, J.-C.; Wong, C. T. T.; Xu, C.; Li, X.-C. J. Am. Chem. Soc. 2013, 135, 6272.

[52] Wong, C. T. T.; Lam, H.-Y.; Song, T.; Chen, G.-H.; Li, X.-C. Angew. Chem., Int. Ed. 2013, 52, 10212.

[53] Bode, J. W.; Fox, R. M.; Baucom, K. D. Angew. Chem., Int. Ed. 2006, 45, 1248.

[54] Fukuzumi, T.; Ju, L.; Bode, J. W. Org. Biomol. Chem. 2012, 10, 5837.

[55] Dawson, P. E.; Muir, T. W.; Clark-Lewis, I.; Kent. S. B. Science 1994, 266, 776 .

[56] Kent, S. B. H. Chem. Rev. Soc. 2009, 38, 338.

[57] Torbeev, V. Y.; Kent, S. B. H. Angew. Chem., Int. Ed. 2007, 46, 1667.

[58] Sohma, Y.; Kent, S. B. H. J. Am. Chem. Soc. 2009, 131, 16313.

[59] Bang, D.; Pentelute, B. L.; Kent, S. B. H. Angew. Chem., Int. Ed. 2006, 45, 3985 .

[60] Mandal, K.; Kent, S. B. H. Angew. Chem., Int. Ed. 2011, 50, 8029.
[61] Huang, Y.-C.; Li, Y.-M.; Chen, Y.; Pan, M.; Li, Y.-T.; Yu, L.; Guo, Q.-X.; Liu, L. Angew. Chem., Int. Ed. 2013, 52, 4858.

[62] Tam, J. P.; Lu, Y. A. Tetrahedron Lett. 1997, 38, 5599.

[63] Tam, J. P.; Lu, Y. A.; Yu, Q. J. Am. Chem. Soc. 1999, 121, 4316.

[64] Tam, J. P.; Wong, C. T. J. Biol. Chem. 2012, 287, 27020.

[65] Warren, J. D.; Miller, J. S.; Keding, S. J.; Danishefsky, S. J. J. Am. Chem. Soc. 2004, 126, 6576.

[66] Chen, J.; Warren, J. D.; Wu, B.; Chen, G.; Wan, Q.; Danishefsky, S. J. Tetrahedron Lett. 2006, 47, 1969.

[67] Botti, P.; Villain, M.; Manganiello, S.; Gaertner, H. Org. Lett. 2004, 6, 4861.

[68] Zheng, J.-S.; Cui, H.-K.; Fang, G.-M.; Xi, W.-X.; Liu. L. ChemBioChem 2010, 11, 511.

[69] Fang, G.-M.; Cui, H.-K.; Zheng, J.-S.; Liu. L. ChemBioChem 2010 , $11,1061$.

[70] Zheng, J.-S.; Chang, H.-N.; Shi, J.; Liu, L. Sci. China Chem. 2012, $55,64$.

[71] Macmillan, D.; Cecco, M. D.; Reynolds, N. L. Santos, L. F. A.; Barran, P. E.; Dorin, J. R. ChemBioChem 2011, 12, 2133.

[72] Taichi, M.; Hemu, X.; Qiu, Y.-B.; Tam, J. P. Org. Lett. 2013, 15, 2620.

[73] Fang, G.-M.; Li, Y.-M.; Shen, F.; Huang, Y.-C.; Li, J.-B.; Lin, Y.; Cui, H.-K.; Liu, L. Angew. Chem., Int. Ed. 2011, 50, 7645.

[74] Fang, G.-M.; Wang, J.-X.; Liu, L. Angew. Chem., Int. Ed. 2012, 51, 10347.

[75] Zheng, J.-S.; Chang, H.-N.; Wang, F.-L.; Liu, L. J. Am. Chem. Soc. 2011, 133, 11080 .

[76] Liang, J.; Fang, G.-M.; Huang, X.-L.; Mei, Z.-Q.; Li, J.; Tian, C.-L.; Liu, L. Sci. China Chem. 2013, 56, 1301.

[77] Zheng, J.-S.; Huang, Y.-C.; Tang, S.; Liu, L. Acc. Chem. Res. 2013, 2013, 46, 2475.

[78] Zheng, J.-S.; Tang, S.; Qi, Y.-K.; Wang, Z.-P.; Liu, L. Nat. Protoc. 2013, 8, 2483.

[79] Li, Y.-M.; Yang, M.-Y.; Huang, Y.-C.; Li, Y.-T.; Chen, P.-R.; Liu, L. ACS Chem. Biol. 2012, 7, 1015.

[80] Zheng, J.-S.; Tang, S.; Guo, Y.; Chang, H.-N.; Liu, L. ChemBioChem 2012, 13, 542.

[81] Tang, S.; Zheng, J.-S.; Yang, K.; Liu, L. Acta Chim. Sinica 2012, $70,1471$.

[82] Wong, C. T. T.; Rowlands, D. K.; Wong, C.-F.; Lo, T. W. C.; Nguyen, G. K. T.; Li, H.-Y.; Tam, J. P. Angew. Chem., Int. Ed. 2012, 51, 5620.

[83] Ji, Y.-B.; Majumder, S.; Millard, M.; Borra, R.; Bi, T.; Elnagar, A. Y.; Neamati, N.; Shekhtman, A.; Camarero, J. A. J. Am. Chem. Soc. 2013, 135, 11623 . 